\title{
O FEDERALISMO MEXICANO: ENTRE A CENTRALIZAÇÃO FISCAL E A DESCENTRALIZAÇÃO POLÍTICA
}

\author{
Bruno de Castro Rubiatti ${ }^{1}$
}

\begin{abstract}
Resumo
$\mathrm{Na}$ maior parte do século XX, o México vivenciou um sistema de partido hegemônico que centralizava as decisões políticas dentro do Partido Revolucionario Institucional (PRI). Somado a isso, o federalismo instaurado em 1917 era altamente centralizado na União, deixando pouca autonomia para as unidades subnacionais. Nesse quadro, não havia espaço político para as oposições, nem partidárias nem territoriais. A situação começa a mudar a partir da década de 1980. Esse artigo trata dessa abertura política, focando na questão da descentralização do federalismo do México a partir de dois eixos: 1) o federalismo fiscal e 2) a descentralização política. O primeiro trata da distribuição de recursos fiscais entre União, estados e municípios, enquanto o segundo centra-se na capacidade das lideranças subnacionais para intervir na política nacional. O quadro apresentado por esse país no início do século XX é distinto do anterior, podendo ser caracterizado como possuindo ainda uma alta centralização fiscal (mesmo que menor que a anterior), mas com um crescente papel das lideranças subnacionais na condução política do país.
\end{abstract}

Palavras-chave: México, Federalismo, Centralização, Descentralização.

\section{Resumen}

En la mayor parte del siglo XX, México experimentó un sistema de partido hegemónico que centraliza las decisiones políticas dentro del Partido Revolucionario Institucional (PRI). Sumado a esto, el federalismo establecido en 1917 fue altamente centralizado en la Unión, dejando poca autonomía para las unidades subnacionales. En este contexto, no había espacio político para la oposición, o partido o territorial. La situación comienza a cambiar a partir de la década de 1980 En este artículo se aborda esta apertura política, centrada en el tema de la descentralización del federalismo en México a partir de dos ejes: 1.) El federalismo fiscal y 2) la descentralización política. La primera trata de la distribución de recursos fiscales entre el gobierno federal, los estados y municipios, mientras que el segundo se centra en la capacidad de los líderes subnacionales de intervenir en la política nacional. El cuadro presentado por este país a principios del siglo XXI es diferente de la anterior, todavía se puede caracterizar por tener una alta centralización fiscal (incluso más pequeño que el anterior), pero con un papel cada vez mayor de líderes subnacionales en la dirección política del país.

Palabras clave: México; Federalismo; descentralización

\begin{abstract}
Mostly of the twentieth century, Mexico has experienced a hegemonic party system that centralized political decisions inside the Partido Revolucionario Institucional (PRI). Added this, federalism established in 1917 was highly centralized in Union, leaving less autonomy for subnational units. At this context, there was no political space for oppositions, not even parties or territorials. The situation begins to change from de 1980. This article treat about this political opening, focusing the decentralization of federalism issue in Mexico from two shafts: 1) the fiscal federalism e 2) the political decentralization. The first one deals with the fiscal resources distribution between the Union, states and municipalities, while the second focuses in subnational leadership capacity to step
\end{abstract}

${ }^{1}$ Doutorando em Ciência Política - Unicamp 
in national politic. The framework presented for this country in beginning of twenty-first century is different from the previous one, and can be characterized as still having high fiscal centralization (even lower than the previous one), but with an increasing leadership subnational role in country political conduct.

Keywords: Mexico, Federalism, Centralization, Decentralization.

\section{INTRODUÇÃO}

Após a Revolução Mexicana de 1917, a história política do México foi marcada por uma forte centralização política. A partir da fundação do Partido Revolucionario Institucional (PRI), em 1946², até a segunda metade da década de 1990, esse país viveu sob um sistema de partido hegemônico, em que o mesmo partido controlava a Presidência, a maioria absoluta das cadeiras na Câmara dos Deputados e do Senado, além dos 32 governos estaduais. Nesse quadro, a estrutura partidária se confunde com as instituições políticas do país, isto é, o chefe do Executivo nacional é o presidente do partido, tendo o controle do acesso às listas partidárias, o que garante ao Presidente grande influência na carreira política dos membros do partido. Somado a isso, o pouco espaço para os partidos de oposição torna a presença na lista de candidatos do PRI uma garantia de sucesso eleitoral. Assim, os recursos políticos necessários estão sob o controle do chefe do Executivo nacional e presidente desse partido. Em suma, estar no PRI e manter uma proximidade com a direção nacional, especificamente com o presidente, é central para a carreira política nesse país.

A partir da década de 1980, essa alta centralização política começa a mudar: o PRI perde espaço nas casas legislativas nacionais (em 1997, esse partido deixa de possuir a maioria absoluta das cadeiras na Câmara dos Deputados e, em 2000, o mesmo ocorre no Senado), na sequência, ocorre, ainda, com a chefia dos Executivos estaduais (o primeiro estado em que o PRI perde o governo é Baja California, em 1989) e, em 2000, o PRI perde pela primeira vez a presidência da República. Esse processo de abertura política foi acompanhado da discussão sobre a descentralização territorial, isto é, a transferência de recursos e responsabilidades para as unidades subnacionais. Apesar disso, essa

\footnotetext{
2 Apesar de surgir como PRI, em 1946, esse partido tem seus antecedentes no PNR (Partido Nacional Revolucionario), fundado em 1929 e no PRM (Partido revolucionario Mexicano), fundado em 1938. O primeiro partido congregava 148 partidos de 28 entidades federativas, formando uma "confederação de partidos”. Em 1933, são extintos os partidos regionais que o formavam, iniciando um processo de centralização das decisões políticas. Já o PRM possuía uma estrutura setorial importante: era integrado pelos grupos camponeses e operários, por elementos militares e por contingentes populacionais. Esse partido pode ser caracterizado como sendo um "partido de corporações" em que as unidades de base eram as organizações mais que os indivíduos
} 
descentralização só teve grandes avanços no terreno normativo, não havendo real transferência nem de recursos nem de responsabilidades para os governos subnacionais.

Esse artigo busca analisar o processo de descentralização política no México. Para tanto, são trabalhadas duas questões: 1) o federalismo fiscal e 2) a descentralização dos recursos políticos, isto é, os instrumentos à disposição das lideranças subnacionais para intervir na política nacional. A partir desses dois eixos, é possível perceber que a situação mexicana conjuga uma ainda alta centralização de recursos fiscais na União, o que dificulta a implementação de políticas e a autonomia de ação dos governadores, com uma considerável descentralização de recursos políticos, o que torna as lideranças subnacionais elementos fortes na condução política e controladores de importantes recursos políticos.

\section{A QUESTÃO FISCAL NO FEDERALISMO MEXICANO}

Mesmo a Constituição Mexicana de 1917 definindo um sistema federal de governo, na prática o poder está altamente concentrado na federação, ou seja, o governo central controla a maioria dos recursos fiscais, caracterizando um excessivo centralismo tanto econômico quanto fiscal do Estado mexicano. Essa aparente contradição entre o federalismo formal e o centralismo real pode ser vista no próprio texto constitucional. Apesar de definir um sistema federal, a mesma constituição prevê amplos poderes discricionários para o Executivo Nacional intervir em grande diversidade de assuntos públicos: matérias de comércio (doméstico e internacional), educação, saúde, trabalho, agricultura, energia, recursos naturais e alimentação são matérias onde o Executivo Nacional tem primazia. Além disso, no decorrer dos anos o governo central também concentrou atributos que eram originalmente concorrentes ou reservados aos estados. Por fim, é faculdade exclusiva desse nível de governo a arrecadação de impostos de renda e sobre o consumo. Por esse motivo, o caso mexicano pode ser "exemplo extremo de disjunção entre as definições constitucionais e o funcionamento efetivo das relações intergovernamentais" (COSTA, 2008, p. 195).

Esse forte centralismo e o virtual descaso pelo tema da descentralização de recursos e competências podem ser entendidos pelo papel exercido pelo PRI na política nacional do México: sem "uma oposição política forte e que poderia legitimamente competir pelo poder, o sistema de pesos e contrapesos em que repousa o federalismo não poderia realmente operar” (MIZRAHI, 2001, p.1). Somada a essa forte presença do PRI na política 
mexicana, o crescimento econômico do México e a estabilidade monetária ${ }^{3}$ ajudavam a manter esse forte centralismo.

Só a partir das reformas eleitorais que possibilitaram uma maior competitividade ao sistema político mexicano, do esgotamento do milagre econômico mexicano (idem, 7) nos anos 1970 e do aumento da representação dos partidos de oposição é que o tema da descentralização ganha força, principalmente nos anos 1990, quando o governo central passa a apresentar programas e propostas de descentralização política e fiscal.

A centralização no México acaba por agravar diversos problemas: o desequilíbrio regional, distribuição desigual de riqueza, pontos de estrangulamento para se garantir o desenvolvimento sustentável do país e baixos níveis de eficiência e eficácia nos serviços públicos prestados pelo governo (idem, p.2). Partindo desse diagnóstico e seguindo as recomendações de instituições internacionais, como o Banco Mundial e o Banco Interamericano de Desenvolvimento, o governo mexicano buscou promover algumas reformas em direção a uma maior descentralização de seus programas sociais, sendo que "a ideia central por detrás destas políticas era que os governos estatais e municipais podiam ser mais eficientes na provisão de bens e serviços públicos porque estão mais perto dos usuários destes serviços que o governo federal e podem, portanto, ser mais sensíveis às necessidades e preferências da população de cada região" (idem, p. 2). Apesar de estas reformas terem sido iniciadas na década de 1970, foi a partir de 1982 que elas ganharam força.

O Plano Nacional de desenvolvimento 1982-1988 propunha a descentralização e a redistribuição de competências entre as instâncias de governo e para tanto ativou os COPLADES (Comité de Planeación para el Desarrollo Estatal) e criou os Convênios Únicos de Desarrolo (CUD). Ambas as instituições tinham por objetivo coordenar a redistribuição de recursos. Entretanto, a centralização continuou em vigor no México, uma vez que o governo federal seguiu retendo o controle sobre o montante, o destino e as condições de distribuição dos recursos aos estados e municípios. Além disso, o governo federal continuava tendo a capacidade para transferir recursos adicionais de forma unilateral, ou seja, sem passar nem por esses dois órgãos responsáveis pela descentralização. Assim, os estados e municípios do país continuavam a depender do governo federal. Em outras palavras, "o padrão tradicional de relações intergovernamentais não foi substancialmente alterado: a subordinação seguiu sendo a base da arquitetura do governo no México entre centro e periferia” (idem, p. 9).

\footnotetext{
3 O México manteve até a década de 1970 uma taxa de crescimento de 6\% e baixos níveis de inflação.
} 
A centralização no caso mexicano fica clara quando olhado o terreno financeiro: apesar de ter tomado algumas medidas administrativas de descentralização, o governo mexicano concentrou ainda mais a capacidade de arrecadação no governo central em detrimento dos entes que compõem a federação. A tabela a seguir mostra essa concentração: como se pode notar a partir de 1923, o percentual de ingressos públicos no México fica concentrado no plano nacional, que é responsável por entre aproximadamente $70 \%$ e $90 \%$ da arrecadação, sobrando pouco espaço para estados e municípios.

Tabela 1: Distribuição percentual dos ingressos públicos por jurisdição de governo no México: 1923-1980

\begin{tabular}{|c|c|c|c|c|c|c|c|c|c|c|c|c|}
\hline & 23 & 30 & 35 & 40 & 45 & 50 & 55 & 60 & 65 & 70 & 75 & 80 \\
\hline Federação & 72,6 & 68,7 & 67,4 & 71,4 & 75,6 & 78,3 & 80,8 & 78,6 & 88,0 & 86,4 & 90,1 & 89,4 \\
\hline Estados & 14,5 & 22,9 & 25,1 & 23,3 & 19,0 & 18,4 & 16,2 & 18,6 & 10,5 & 12,0 & 8,6 & 9,4 \\
\hline Municípios & 12,9 & 8,4 & 7,4 & 5,3 & 3,4 & 3,3 & 2,9 & 2,8 & 1,5 & 1,6 & 1,3 & 1,1 \\
\hline
\end{tabular}

Fonte: Herrera (2006, p. 10)

Na década de 1980, ocorreu uma reforma fiscal que, visando melhorar o sistema de arrecadação, acabou por unificar o imposto sobre o consumo e colocá-lo sob competência exclusiva da federação. Antes dessa reforma cabia aos estados cobrar os "impostos sobre ingressos mercantis" e, para abrir mão desta fonte de arrecadação financeira, os estados receberiam transferências dos impostos arrecadados pela união com base em fórmulas préestabelecidas. Isso acabou por aumentar a dependência de estados e municípios frente à união ${ }^{4}$.

O quadro financeiro para os estados e municípios mexicanos é bastante precário. Para os primeiros, só fica disponível a arrecadação de impostos sobre a folha de pagamentos e a cobrança de alguns serviços públicos, como a expedição de carteiras de motorista, o imposto sobre a propriedade de automóveis e as certidões de nascimento. Já para os municípios a situação é ainda mais crítica, uma vez que muitos deles não têm condições nem capacidade real de aumentar suas arrecadações próprias. Assim, o quadro do federalismo mexicano continua sendo o de alta centralização fiscal, com forte dependência financeira dos entes subnacionais ao governo central. Somado a isso, muitos dos recursos transferidos aos estados e municípios continuam sendo atribuídos pela união de maneira discricionária,

\footnotetext{
4 Em 1988, o governo federal exercia 88,4\% do gasto total, enquanto os estados exerciam 9,8\% e os municípios 1,8\%. Além disso, nesse mesmo ano, os estados dependiam em média em $61 \%$ das transferências de recursos do governo federal (MIZRAHI, 2001).
} 
[...] frequentemente o montante destes recursos dependiam estritamente da relação pessoal entre o governador e o presidente da república. Ademais, a maioria desses recursos vinha condicionada a uma série de restrições que deixavam aos governos estatais e municipais pouca margem de manobra para definir suas próprias prioridades e atender suas necessidades (MIZRAHI, 2001, p. 13)

O final da década de 1980 acaba por trazer uma mudança no quadro político mexicano: apesar do PRI ganhar a presidência, ele perde em alguns estados, o que impõe ao presidente eleito em 1988 - Carlos Salinas de Gortari - a necessidade de negociação com a oposição. Durante esse governo, houve um aumento das transferências de recursos da união para os estados e municípios ${ }^{5}$. Entretanto, essa transferência não significou um aumento da autonomia dos estados e municípios frente à união uma vez que as decisões mais importantes de como exercer os recursos transferidos continuavam a cargo do governo central e, com exceção das participações federais, os recursos transferidos pela união seguiam sendo, muitas vezes, atribuídos de forma discricionária e com base políticoeleitoral (MIZRAHI, 2001, p. 13).

Assim, apesar de alguns avanços em direção a uma maior descentralização, o federalismo mexicano continuava a ser altamente centralizado, mas, comparado com o período anterior, é possível perceber que estados e municípios tiveram alguns ganhos no decorrer da década de 1980. Mas foi apenas na década de 1990, principalmente depois da vitória de Zedillo (1994) para a Presidência da República, que houve reais avanços na descentralização no México. Esse presidente, eleito pelo PRI, adotou a descentralização como política prioritária de seu governo, uma vez que considerava o excessivo centralismo político e econômico "um dos mais sérios obstáculos para se reverter os problemas de desigualdade social, desequilíbrio regional e deterioração dos níveis de vida da população" (idem, p.17). Para tanto, o governo central defendia um "Novo Federalismo", que propunha: 1) reformar as relações financeiras entre os diferentes níveis de governo, 2) reduzir o poder discricionário da presidência, 3) fortalecer os governos estaduais e municipais, 4) impulsionar uma efetiva separação entre os poderes Executivo, Legislativo e Judiciário, 5) promover uma maior transparência nos processos eleitorais, e 6) contribuir na democratização da vida pública.

Durante esse governo (1994-2000) ocorreram avanços efetivos no que tange a descentralização do federalismo mexicano: aumentaram os recursos transferidos aos estados e municípios, financiamentos de programas de capacitação para autoridades

\footnotetext{
${ }^{5}$ Em 1993, o governo federal exercia $64,5 \%$ do gasto total, enquanto os estados passaram a exercer 30,5\% (idem, p.13).
} 
municipais, os estados passaram a exercer funções referentes à agricultura, meio ambiente, construção e manutenção de estradas, segurança pública, além de uma reforma constitucional que garantiu maiores faculdades aos municípios. Entretanto, segundo Herrera (2006, p.18), o governo de Zedillo "aprofundou a descentralização, porém o fez atendendo mais à negociação política do que a necessidade de reformar as instituições do federalismo fiscal". Em suma, na década de 1990, o federalismo mexicano passa a ser mais descentralizado do que antes, aumentando as funções dos estados e municípios na execução de políticas públicas; entretanto, a distribuição de recursos continuava a ser efetuada pelo Executivo Nacional, obedecendo a critérios políticos.

Assim, todas essas mudanças não anularam o caráter centralizado do federalismo do México. Esse centralismo pode ser percebido através de: 1) a maior parte dos gastos seguirem sob o controle da união, a despeito do crescimento da participação dos estados e municípios; 2) os estados e municípios, que seguem cada vez mais dependentes das transferências do governo central (participações, transferências e contribuições), uma vez que não possuem a faculdade para aumentar seus ingressos próprios através de uma maior arrecadação de impostos; 3) as transferências e as contribuições que chegam aos estados e municípios, muitas vezes destinadas a projetos específicos, o que reduz consideravelmente a autonomia dos governos subnacionais no que tange aos gastos realizados; 4) a maior parte dos recursos não condicionados (as participações) se destinarem a pagar os gastos correntes, o que diminui a capacidade de investimentos desses governos; 5) ambiguidades que persistem na distribuição de responsabilidades entre os níveis de governo, 6) os maiores beneficiados terem sido os municípios e não os estados, mesmo com o crescimento das transferências para os governos subnacionais, o que debilitou a capacidade dos estados para planejar e tomar decisões sobre seus gastos, 7) a transferência de recursos, que não reconheceu a diversidade municipal e estadual, ou seja, nem todos os estados e municípios têm as mesmas capacidades para exercer o gasto (MIZRAHI, 2001, pp. 17-20).

As eleições de 2000 representam uma importante ruptura na história política mexicana: a eleição de um membro do PAN como Presidente da República - Vicente Fox. Essa eleição tem importante impacto sobre as relações intergovernamentais, uma vez que esse governo não controlava nem o Congresso nacional, nem os principais governos estaduais (COSTA, 2008, p. 196). Por esse motivo, o governo Fox buscou fortalecer as relações intergovernamentais, principalmente entre o governo federal e os municípios, 
estratégia essa que lhe permitiu contornar as dificuldades impostas pelo controle do PRI sobre o congresso e parte dos governos estaduais (MIZRAHI, 2005).

É importante destacar que mesmo o início da alternância e o final do período de partido hegemônico não proporcionaram uma mudança substancial nas instituições do federalismo fiscal do México. Mesmo os esforços por descentralização das décadas de 1990 e 2000 não mudaram o caráter centralizador desse federalismo, em que o Executivo mantém a maior parte da arrecadação e possui instrumentos que lhe permitem distribuir esses recursos de maneira política, não contando com critérios claros para essa distribuição. Isso faz com que, em boa parte das políticas, os estados só administrem fundos federais, tendo sua capacidade de decisão sobre a utilização desses recursos praticamente anulada. No México, "apesar do discurso político, a realidade tem sido outra e os governos locais têm poucas atribuições de arrecadação e o gasto se exerce atado a programas federais ou baixo à supervisão deste" (HERRERA, 2006 p. 45).

Em suma, o federalismo mexicano, assim como todo o sistema político, passou por transformações nas últimas décadas. Houve crescimento da descentralização e aumento das capacidades políticas e financeiras dos governos subnacionais. Segundo Falleti (2010, p.28), o grau de autonomia subnacional no México teria passado, depois da primeira onda de descentralização, de baixo-médio para médio. Todavia, o federalismo fiscal do México ainda sofre com a debilidade institucional, o que não permite que as entidades federativas “desenhem, instrumentem, avaliem e fiscalizem uma política própria de finanças públicas" (HERRERA, 2006, p. 3). Assim, o ponto principal da política mexicana continua a ser o governo central. Este nível de governo ainda concentra a maior parte dos recursos disponíveis e possui fortes poderes discricionários, o que torna os outros níveis de governo dependentes dele. A falta de capacidade tributária causa a dependência dos governos estaduais e municipais frente ao governo federal. Por fim, as decisões políticas sobre os programas estatais ficam a cargo do governo central, cabendo às entidades subnacionais, no melhor dos casos, o papel de executoras dos programas formulados no centro da federação.

\section{DESCENTRALIZAÇÃO POLÍTICA NO MÉXICO}

Seguindo o processo de abertura política da década de 1980, o federalismo mexicano também passa a ter maior impacto sobre as decisões políticas deste país. Como dito anteriormente, até 1989, o PRI controlava o Executivo Nacional, as maiorias em 
ambas as casas legislativas que compõem o Congresso Nacional e a totalidade dos governos subnacionais. Tendo em mente que o sistema político mexicano era altamente centralizado na figura do Presidente, pois, apesar de não gozar de grandes poderes legislativos constitucionais, o chefe do Executivo Nacional também era o líder do partido hegemônico, conclui-se que havia baixo espaço para a expressão das demandas subnacionais. Nesse período, o Congresso nacional se limitava a aprovar as medidas oriundas do Executivo (NACIF, 2007) e nenhuma das câmaras atuava no sentido de representar os interesses dos estados que compõem a federação mexicana. Somado a isso, o controle exercido pelo chefe do Executivo, enquanto líder partidário, tornava o PRI um partido com alta dose de disciplina e, sendo os governadores membros desse partido, não havia grandes possibilidades de se formar uma oposição dos governadores aos projetos oriundos daquele poder.

Entretanto, esse quadro sofre uma mudança gradual, assim como ocorreu com o federalismo no âmbito financeiro. Todavia, os dois processos possuem diferenças significativas tanto temporalmente quanto na profundidade de seus efeitos. Em resumo, a situação dos governos subnacionais pode ser caracterizada como de baixa autonomia financeira e crescente influência política. O processo de descentralização financeira foi sumarizado na seção anterior. Assim, aqui cabe destacar a descentralização no âmbito político.

Um primeiro ponto a se tratar são os poderes constitucionais das lideranças estaduais - em especial, dos governadores - sobre o calendário eleitoral. Diferentemente do Brasil, não há um calendário eleitoral unificado no México, isso é, no que tange a questão do calendário eleitoral, a Constituição Mexicana dá grande liberdade para o nível estadual escolher seu calendário: define que os mandados dos governadores dos estados não podem durar mais que seis anos, as eleições têm que ser diretas, os deputados estaduais são eleitos por princípio de maioria relativa e de representação proporcional. Entretanto, a Constituição não determina nenhum tipo de calendário eleitoral, deixando isso por conta das leis estaduais. Além disso, a duração dos mandatos é diferente: para presidente, senadores e governadores, é de seis anos, enquanto que para deputados estaduais e federais é de três anos. Isso faz com que as eleições para Legislativo e Executivo Federal só coincidam a cada seis anos, sendo que a Câmara dos Deputados sofre uma renovação total no meio do período presidencial. As eleições para deputados estaduais também ocorrem a cada três anos. Assim, o país apresenta tanto eleições casadas para os cargos do Congresso 
e do Executivo nacional quanto eleições isoladas, o mesmo ocorrendo no nível estadual. O ritmo eleitoral para governadores e membros dos Legislativos estaduais é regulado pelas Constituições dos próprios estados, podendo coincidir com as eleições nacionais ou não. Essa alta liberdade na formulação do calendário eleitoral nos estados permite que as lideranças subnacionais possam escolher "casar" suas eleições com as nacionais - o que tornaria o eixo central do pleito a escolha do Executivo nacional - ou isolá-las - tornando a disputa para o cargo de governador o elemento aglutinador dessas eleições. Assim, de acordo com a estratégia dessas lideranças, o calendário eleitoral pode fortalecer o governo central ou o estadual como eixo.

Por causa dessa grande liberdade para os estados formularem seus próprios calendários eleitorais, temos uma grande variedade de anos eleitorais nos 32 estados mexicanos: de 1989 até 2010, em apenas quatro anos não ocorreram eleições para governador: 1990, 1996, 2002 e 2008. Cabe destacar que, desses quatro anos, em três ocorreram eleições para deputados estaduais em algum dos entes que formam a federação mexicana: em 1996, isso ocorreu em Nayrit, em 2002 e 2008, além de eleições para deputados estaduais nesse estado, ocorreram também em Baja California, Coahuila, Guerrero e Quintana Roo (BADILLO e RAMÍREZ, 2009, p. 22-2). Fora isso, em todos os anos em que ocorrem eleições nacionais - tanto para Congresso e Presidência, quanto nas eleições intermediárias para a Câmara dos Deputados - ocorrem também eleições em alguns dos estados que compõem a federação mexicana.

Ainda sobre as eleições, cabe destacar os momentos em que se iniciaram as alternâncias de partidos na chefia dos executivos estaduais. $O$ primeiro estado em que o PRI perde a eleição para governador foi Baja California, em 1989, oito anos antes da formação do primeiro governo dividido no âmbito federal (1997). Ainda no governo Salinas de Gortari, mais dois estados foram perdidos pelo, até então, partido hegemônico: Guanajuato (1991) e Chihuahua (1992). Já no governo de Ernesto Zedillo mais 10 estados foram perdidos pelo PRI. Cabe destacar que na primeira metade do mandato desse presidente - o último do PRI até 2012 - o PRI ainda controlava maiorias absolutas tanto na câmara quanto no senado, fato que muda em 1997, quando esse partido perde pela primeira vez a maioria na Câmara dos Deputados. Assim, antes de se formar o primeiro governo dividido, o PRI perde mais um governo estadual e mais nove após essa instauração.

No total, 22 dos 32 estados mexicanos conheceram a alternância entre 1988 e 2012, sendo que 18 deles o fizeram após 1997. Cabe destacar que em 12 deles, o PRI recuperou o 
governo posteriormente e em três deles houve nova mudança no partido do governo. Assim, o fenômeno da alternância tem uma disseminação considerável entre os estados mexicanos: quase $70 \%$ deles tiveram pelo menos uma troca de partido no comando do Executivo estadual.

Esse fenômeno é relevante pois, como foi dito anteriormente, a centralização do federalismo mexicano é, em parte, explicada pelo papel de partido hegemônico exercido pelo PRI. Assim, podemos observar que Salinas de Gortari não teve que enfrentar um número significativo de governadores oriundos das fileiras de oposição: em seus seis anos de governo, apenas três estados foram governados por um partido diferente do seu. $\mathrm{O}$ mesmo não ocorre com Zedillo, uma vez que durante seu governo o número de governadores de outros partidos salta para 12 , ou seja, a oposição chefiava $37,5 \%$ dos governos estaduais.

Tabela 2: Alternância política dos governadores nos estados mexicanos: 1989-2012

\begin{tabular}{|c|c|c|c|c|}
\hline & Estado & $\begin{array}{c}\text { Ano da } \\
\text { alternância }\end{array}$ & $\begin{array}{l}\text { Partido } \\
\text { ganhador }\end{array}$ & $\begin{array}{c}\text { Recuperado } \\
\text { pelo PRI }\end{array}$ \\
\hline \multirow{3}{*}{$\begin{array}{ll}\text { Carlos } & \text { Salinas } \\
\text { de } & \text { Gortari } \\
(1988-1994)\end{array}$} & Baja California & 1989 & PAN & - \\
\hline & Guanajuato & 1991 & PAN & - \\
\hline & Chihuahua & 1992 & PAN & 1998 \\
\hline \multirow{10}{*}{$\begin{array}{l}\text { Ernesto Zedillo } \\
\text { Ponce de Leon } \\
(1994-2000)\end{array}$} & Jalisco & 1995 & PAN & 2012 \\
\hline & Nuevo león & 1997 & PAN & 2003 \\
\hline & Querétaro & 1997 & PAN & 2009 \\
\hline & Aguascalientes & 1998 & PAN & 2010 \\
\hline & Zacatecas & 1998 & PRD & 2010 \\
\hline & $\begin{array}{l}\text { Baja California } \\
\text { Sur }\end{array}$ & 1999 & PRD-PT & 2011 (PAN) \\
\hline & Tlaxcala & 1999 & PRD-PT-PVEM & 2005 (PAN) \\
\hline & Nayrit & 1999 & $\begin{array}{c}\text { PAN-PRD-PT- } \\
\text { PRS }\end{array}$ & 2011 \\
\hline & Chiapas & 2000 & $\begin{array}{l}\text { PAN-PRD-PT- } \\
\text { PVEM-PSN- } \\
\text { PCD-PAS-PC }\end{array}$ & 2005 \\
\hline & Morelos & 2000 & PAN & 2012 (PRD) \\
\hline \multirow{4}{*}{$\begin{array}{lr}\text { Vicente } & \text { Fox } \\
\text { Quesada } & (2000- \\
\text { 2006) } & \end{array}$} & Michoacán & 2001 & $\begin{array}{l}\text { PRD-PT-PVEM- } \\
\text { PSN-PAS-PC }\end{array}$ & 2007 \\
\hline & Yucatán & 2001 & $\begin{array}{l}\text { PAN-PRD-PT- } \\
\text { PVEM }\end{array}$ & 2007 \\
\hline & San Luis Potosí & 2003 & PAN & 2009 \\
\hline & Guerrero & 2005 & PRD-PT-PRS & - \\
\hline \multirow{3}{*}{$\begin{array}{l}\text { Felipe Calderón } \\
\text { Hinojosa (2006- } \\
\text { 2012) }\end{array}$} & Sonora & 2009 & PAN & - \\
\hline & Sinaloa & 2010 & PAN & - \\
\hline & Oaxaca & 2010 & $\begin{array}{l}\text { PAN-PRD- } \\
\text { CONV-PT }\end{array}$ & - \\
\hline
\end{tabular}




\begin{tabular}{cccc}
\cline { 2 - 4 } Puebla & 2010 & PAN-PRD- & - \\
& & COV-PANAL & - \\
Tabasco & 2012 & PRD-PT-MC & - \\
\hline
\end{tabular}

Fonte: Santiago (2013, p. 6)

O quadro para as relações intergovernamentais se torna mais complexo no primeiro governo do $\mathrm{PAN}^{6}$. Vicente Fox, ao contrário de seus antecessores, não contou com uma maioria de governadores de seu partido: em todo o período apenas 11 estados eram governados pelo PAN, sendo que esse partido perde a chefia do Executivo estadual em dois desses estados ainda no governo Fox - Neuvo Leon, em 2003, e Nayrit, em 2005. Fora isso, durante seus seis anos de governo o seu partido só ganha eleições para o governo de dois estados - Yucatán e San Luis Potosí. O quadro para seu sucessor - Felipe Calderón, também do PAN - foi ainda mais complicado: em 2006 apenas 9 estados eram governados pelo PAN, sendo que esse partido perde quatro desses estados no decorrer do mandato, mas conquista outros quatro em 2009 e 2010. Assim, o que se pode notar é que os presidentes pós-alternância não puderam contar com a maioria dos governadores em suas bases partidárias, o que torna a negociação entre os níveis de governo mais intensas e complexas.

Apesar da alternância ter atingido diversos estados desde 1989, ainda se pode notar a persistência da preponderância do PRI na maior parte das disputas estaduais mesmo após as vitórias do PAN nas eleições presidenciais de 2000 e 2006. Como se pode ver na tabela 3, em todos os períodos o PRI é o vencedor na grande maioria das eleições realizadas e os outros dois partidos principais - PAN e PRD - contam com um número bem menor de vitórias nas eleições para os governos estaduais. Cabe destacar que o quadro abaixo reforça a visão de um sistema de três partidos principais uma vez que são eles os responsáveis por ganhar todas as eleições para os executivos estaduais, já que os quatro casos marcados como "outro" na tabela 3 se referem a alianças formadas pelo PRD e PAN apoiando um candidato externo a ambos. Segundo Valdes (2013, p 6), essas alianças, mesmo não sendo um fenômeno estranho na política mexicana, têm ganhado importância como estratégia competitiva nos últimos tempos.

\footnotetext{
${ }^{6}$ Partido Acción Nacional. Principal opositor do PRI durante o período de partido hegemônico. Junto com o PRD (Partido de la Revolución Democrática) e o próprio PRI, compõe os três principais partidos políticos do México.
} 
Tabela 3: Quantidade de vitórias eleitorais para presidente e governadores por partido político no México: 1976-2011

\begin{tabular}{|c|c|c|c|c|c|}
\hline & \multirow{2}{*}{$\begin{array}{c}\text { Eleição } \\
\text { Presidencial }\end{array}$} & \multicolumn{4}{|c|}{ Eleições para governador } \\
\hline & & PAN & PRI & PRD & Outro \\
\hline $1976-1981$ & PRI & 0 & 28 & - & 0 \\
\hline 1982-1987 & PRI & 0 & 31 & - & 0 \\
\hline 1988-1993 & PRI & 1 & 30 & 0 & 0 \\
\hline 1994-1999 & PRI & 6 & 21 & 4 & 1 \\
\hline 2000-2005* & PAN & 9 & 18 & 6 & 0 \\
\hline 2006-2011 & PAN & 6 & 20 & 3 & 3 \\
\hline
\end{tabular}

*Nesse período se celebraram três eleições extraordinárias: Uma no caso de Chiapas (2001) devido às impugnações das eleições de 2000, as outras duas restantes ocorreram em Colima (2003), devido às impugnações das eleições ocorridas no mesmo ano e outra em 2005 para eleger um governador substituto.

Fonte: Valdes (2013, p. 6)

Por fim, um último elemento a ser tratado sobre as eleições para os governos estaduais no México é a competitividade. A partir do número efetivo de partidos $(\mathrm{NEP})^{7}$ das disputas para presidente e governadores, vemos impacto da abertura política: se entre 1976 e 1993 a média do NEP para as disputas pelo Executivo estadual não chegava a 2, temos hoje um quadro em que esse mesmo indicador chega a aproximadamente 2,5. Claro está que esse patamar é consideravelmente inferior ao atingido nas disputas presidenciais que entre 1988 e 1993 chegava a 2,64 e na eleição de 2006 foi de 3,15. Porém, a variação do NEP nas disputas entre os estados é grande, isto é, ocorrem casos em que a disputa ainda é baixa e outros onde a mesma se encontra em patamar superior ao atingido no plano nacional. Por esse motivo os NEPs máximos e mínimos merecem destaque.

Como se pode ver na tabela 4, ainda há estados no México em que a disputa é muito baixa: ao olharmos a evolução do NEP mínimo nesse nível, temos que ainda há estados em que esse índice não chegou a 2. Em contrapartida, há estados em que essa disputa superou a marca de 3 já no período entre 1994-1999 - o que só vem a ocorrer no plano nacional em 2006. Assim, o que se tem é uma grande variação no nível de abertura e competição entre os estados mexicanos e um aumento da incongruência desse grau de competição entre os níveis nacional e estadual.

\footnotetext{
${ }^{7} \mathrm{O}$ Número efetivo de partidos é calculado a partir da seguinte maneira: $\mathrm{NEP}=1 / \Sigma \mathrm{pe}^{2}$, onde pe $=$ percentual de votos conquistados pelos partidos
} 
Tabela 4: Números efetivos de partidos nas eleições para presidente e governadores no México: 1976-2011

\begin{tabular}{ccccccc}
\hline & $\mathbf{1 9 7 6 - 1 9 8 1}$ & $\mathbf{1 9 8 2 - 1 9 8 8}$ & $\mathbf{1 9 8 9 - 1 9 9 3}$ & $\mathbf{1 9 9 3 - 1 9 9 9}$ & $\mathbf{2 0 0 0 - 2 0 0 5}$ & $\mathbf{2 0 0 6 - 2 0 1 1}$ \\
\hline $\begin{array}{c}\text { NEP } \\
\text { Presidente }\end{array}$ & 1,16 & 1,84 & 2,64 & 2,84 & 2,87 & 3,15 \\
\hline $\begin{array}{c}\text { NEP } \\
\text { máximo para } \\
\text { governador }\end{array}$ & 1,90 & 2,48 & 2,49 & 3,29 & 3,34 & 3,34 \\
$\begin{array}{c}\mathbf{N E P} \\
\text { mínimo para } \\
\text { governador }\end{array}$ & 1,00 & 1,04 & 1,16 & 1,35 & 1,86 & 1,52 \\
\hline $\begin{array}{c}\text { Média para } \\
\text { governadores }\end{array}$ & 1,29 & 1,52 & 1,52 & 2,54 & 2,46 & 2,45 \\
\hline Fonte: Valdes & & & & & &
\end{tabular}

Fonte: Valdes (2013, p. 7)

Assim, o que se nota é uma diferenciação entre os dois níveis de Executivo - o nacional e os estaduais - o que muda o quadro das relações intergovernamentais: se antes da alternância o chefe do Executivo era o líder partidário e os governadores eram membros desse mesmo partido - o que garantia certa congruência de interesses -, as demandas subnacionais não encontravam espaço institucional para serem processadas, o mesmo não ocorrendo no período atual, quando partidos de oposição ocupam as chefias dos Executivos estaduais e são concorrentes reais nas eleições nesse nível de governo. Ou seja, sob o sistema de partido hegemônico, o PRI era a instituição política que assegurava o funcionamento do sistema político, isto é, era o principal “órgão de integração dos diversos atores e grupos políticos dentro do regime, assim como em seu 'interior' era onde se levava a cabo a distribuição dos cargos de eleição pública" (VALDES, 2013, p.2). Nesse sentido, como o Presidente da República era o presidente do PRI, o que lhe garantia o controle dos recursos políticos necessários para o sucesso eleitoral dos postulantes a cargos eletivos de seu partido, era através desse partido que se dava a negociação entre os planos nacional e subnacionais, sendo que nessa negociação o plano nacional e o presidente tinham grande vantagem. Com o início da abertura política, com o aumento da competição e com governadores de outros partidos eleitos, a relação entre esses dois níveis ganha outro contorno, isto é, não mais ocorre "dentro dos muros" do PRI.

Cabe destacar que isso não significa que o Executivo nacional não tenha instrumentos para induzir a cooperação dos governadores. O principal deles é o controle financeiro exercido pelo nível nacional, como foi descrito na seção anterior desse artigo.

Além da questão das eleições para governadores, outro elemento importante para a análise da descentralização política do federalismo mexicano é a referente aos Congressos 
estaduais. Isso ocorre por dois motivos: 1) as reformas constitucionais no México devem ser aprovadas por dois terços de ambas as câmaras que compõem o Congresso nacional e pela maioria das legislaturas estaduais (artigo 135) e 2) a mesma constituição faculta às legislaturas dos estados o poder de iniciar projetos de lei (artigo 71).

Sobre o primeiro ponto, é importante notar que o partido do Presidente após a alternância não consegue formar maioria nos Legislativos estaduais: no governo Fox, o PAN só havia conseguido essa maioria em 4 dessas Casas - aproximadamente em 13\% das assembleias - quadro diferente do encontrado por Zendillo que, mesmo após a formação do governo dividido em 1997 ainda podia contar com 22 Legislativos estaduais com maioria do PRI - 69\%. Somado a isso, a maioria conseguida pelo PAN nas assembleias legislativas estaduais não chegava a 50\%, isto é, não eram Legislativos que contavam com uma maioria absoluta do PAN. Assim, seguindo o disposto na Constituição, o governo de Fox encontraria maiores dificuldades para aprovar reformas constitucionais, o que levaria a um maior esforço de negociação entre os partidos e líderes estaduais.

Entre 2001 e 2009, ocorreram 93 processos eleitorais para deputados estaduais no México, e em $61 \%$ desses processos o PRI foi o partido mais votado, ou seja, mesmo após a alternância, a presença do antigo partido hegemônico continua forte nesse nível do Legislativo. Somado a isso, tem-se que nas legislaturas vigentes em 2009, o PRI contava com maioria absoluta em 16 Legislativos estaduais, enquanto o PAN gozava do mesmo status em apenas 1 - o PRD não formou maioria absoluta em nenhum legislativo estadual. Assim, o PRI possuía maioria absoluta em 50\% dos Legislativos estaduais (BADILLO e RAMÍREZ, 2009).

Já sobre a participação dos Legislativos estaduais na produção do Legislativo nacional, cabe analisar sua participação no que tange à iniciativa e aprovação de projetos de lei em ambas as casas do Congresso Nacional mexicano.

Tabela 5: Iniciativas dos Legislativos estaduais na Câmara dos Deputados e Senado do México: 1991- 2012

\begin{tabular}{llllllll}
\hline & $\mathbf{1 9 9 1 -}$ & $\mathbf{1 9 9 4 -}$ & $\mathbf{1 9 9 7 -}$ & $\mathbf{2 0 0 0 -}$ & $\mathbf{2 0 0 3 -}$ & $\mathbf{2 0 0 6 -}$ & $\mathbf{2 0 0 9 -}$ \\
& $\mathbf{1 9 9 4}$ & $\mathbf{1 9 9 7}$ & $\mathbf{2 0 0 0}$ & $\mathbf{2 0 0 3}$ & $\mathbf{2 0 0 6}$ & $\mathbf{2 0 0 9}$ & $\mathbf{2 0 1 2}$ \\
\hline Senado & 0 & 12 & 2 & 15 & 12 & 15 & 28 \\
Deputados & 2 & 1 & 33 & 83 & 117 & 97 & 79 \\
\hline
\end{tabular}

Fonte: Nacif (2006); Sistema de Información Legislativa

(http://sil.gobernacion.gob.mx/portal/Numeralia/iniciativas) 
Como se pode notar na tabela 5, após a instauração dos governos divididos em 1997, há um crescimento das propostas oriundas dos Legislativos estaduais no Congresso, em especial na Câmara dos Deputados. Entretanto, cabe destacar que mesmo com esse crescimento, a participação das assembleias estaduais em ambas as câmaras é baixa: para o Senado essa participação fica em torno de 1 e $2 \%$ na maior parte do período - com exceção para 1994-1997, quando esse patamar foi de 14\% e 2000-2003 quando foi de 3,4\% das propostas iniciadas nessa casa. Já na Câmara dos Deputados essa participação é de 1\% no período sob o sistema de partido hegemônico (1991-1994 e 1994-1997) e varia entre $6,9 \%$ e $2,1 \%$ durante os governos divididos. Apesar de ter baixo impacto sobre o montante de leis iniciadas, cabe destacar que os legislativos estaduais tiveram uma maior participação na apresentação de projetos de lei na câmara dos deputados se comparados com o Executivo nacional.

A tabela 6 apresenta os dados referentes ao número de projetos iniciados pelos Legislativos estaduais que chegaram a aprovação.

Tabela 6: Projetos aprovados oriundos dos legislativos estaduais do México: 19912012

\begin{tabular}{llllllll}
\hline & $1991-$ & $1994-$ & $1997-$ & $2000-$ & $2003-$ & $2006-$ & $2009-$ \\
& 1994 & 1997 & 2000 & 2003 & 2006 & 2009 & 2012 \\
\hline Senado & 0 & 0 & 0 & 1 & 1 & 3 & 0 \\
Deputados & 1 & 1 & 4 & 17 & 17 & 10 & 1 \\
\hline
\end{tabular}

Fonte: Nacif (2006); Sistema de Información Legislativa

(http://sil.gobernacion.gob.mx/portal/Numeralia/iniciativas)

Como se pode notar, o número de propostas vindas dos legislativos estaduais que chegam a uma sanção positiva definitiva é baixa: dos 496 projetos iniciados por esses legislativos nas duas câmaras do Congresso nacional, apenas 56 foram aprovados, ou seja, $11,3 \%$ das propostas dos legislativos estaduais são efetivamente transformadas em leis. Essa taxa de sucesso pode ser vista como baixa, uma vez que é menor que a atingida por Deputados e Senadores e fica bem abaixo da apresentada pelo Executivo ${ }^{8}$. Além disso, a participação dessas assembleias no total da produção legislativa dessas câmaras é residual: no Senado essa participação fica entre 0 e $1,2 \%$ e para a Câmara dos Deputados a participação fica entre $0,5 \%$ e 5,5\%. Assim, esses dados corroboram o que foi afirmado por

\footnotetext{
8 A taxa de sucesso média para o período é de 19,5 para o Senado, 15,8 para os Deputados e 83,1 para o Executivo.
} 
Algazi (2012, p. 632) de que "a descentralização política registrada no país não se expressa através da apresentação de propostas de lei por via dos Congressos estaduais".

Entretanto, cabe ainda destacar o destino dos projetos oriundos dos Legislativos estaduais, isto é, se eles iniciam seus trâmites pela câmara dos deputados ou pelo Senado prioritariamente. Sobre esse ponto, os projetos desses legislativos são iniciados pelo Senado em apenas 16,9\% das vezes, ficando a Câmara dos Deputados com 83,1\%. O mesmo se repete quando olhamos os projetos aprovados oriundos desses legislativos: 8,9\% dos projetos das assembleias estaduais que foram aprovados iniciaram seu trâmite no Congresso nacional pelo Senado e 91,1\% pela câmara baixa. O mesmo se repete na taxa de sucesso desses projetos em cada uma das Câmaras Legislativas do Congresso Nacional do México: 5,9 no Senado e 12,4 na Câmara dos Deputados. Esses dados mostram que as iniciativas dos legislativos estaduais não priorizam a casa do Congresso Nacional, que tem por função a representação territorial, ou seja, ao invés de terem seus projetos iniciados pelo Senado, os legislativos estaduais acabam por priorizar a Câmara dos Deputados. Somado a isso, temos que a taxa de sucesso desses legislativos é superior na câmara baixa, ou seja, os projetos dos legislativos estaduais que se iniciam no Senado encontram maiores obstáculos para serem aprovados. Em suma, a casa que, por definição representa os entes federados, é mais refratária aos projetos oriundos dos legislativos estaduais que a câmara populacional.

Outro impacto da abertura política que aumentou o papel das lideranças subnacionais foi a alteração na organização interna dos partidos, sendo que o primeiro a sofrer tal impacto foi o PRI. Segundo Casar (2008, p. 228), o novo sistema eleitoral ocasionou três transformações nesse partido, a dizer: 1) terminou com a certeza de que aparecer nas listas para eleição popular equivalia praticamente à obtenção do cargo, o que obriga o PRI a procurar candidatos realmente competitivos, 2) forçou a negociação com outros partidos, pois não detinham mais a maioria necessária para aprovar suas iniciativas e 3) a perda da presidência foi acompanhada pelo desaparecimento da liderança "real" do partido. Sobre o terceiro ponto, a autora afirma que

[...] a disciplina, baseada fundamentalmente no poder do presidente para controlar as carreiras políticas dos membros do partido, perdeu seu principal controlador. Os líderes das câmaras começaram a submeter-se à votação das bancadas, os militantes ativos adquiriam o poder para decidir quem deveria ser o líder do partido e os governadores deixaram de ter o centro como fator decisivo para a permanência no cargo (CASAR, 2008, p. 228). 
Assim, o final do período de partido hegemônico leva a uma maior independência dos líderes subnacionais do PRI, que não mais dependiam exclusivamente do apoio da presidência para permanecer em seus cargos. Fora isso, a abertura também alterou as práticas de organização nos outros dois partidos principais do México, uma vez que a "ampliação das possibilidades de triunfo tanto nas eleições presidenciais quanto nas legislativas, junto com a entrada de enormes recursos públicos provenientes da nova legislação eleitoral, a ampliação dos grupos parlamentares e de governos locais que foram ganhando, desataram a luta pelas candidaturas e lideranças partidárias" (CASAR, 2008, p. 228).

Esse novo quadro político faz com que os membros eleitos para o Congresso nacional tenham que atender a vários atores políticos que, muitas vezes apresentam expectativas diversas, ou mesmo conflitantes, isto é, "seu comportamento se vê exposto a diversas pressões cruzadas" (ALGAZI, 2012, p. 633). Isto é, além de atender as demandas oriundas da liderança nacional do partido, têm também que atender os interesses de outros atores que "por sua posição, capacidade organizacional ou acesso a outros recursos de poder, podem lhes proporcionar desde a estrutura estadual ou municipal um porvir na política" (ALGAZI, 2012, p. 633). Assim, a queda do sistema de partido hegemônico propiciou uma maior independência para as lideranças subnacionais frente ao centro. Isso acaba por fortalecer a influência dessas lideranças - em especial dos governadores - sobre os legisladores no plano nacional, uma vez que a proibição de reeleição acaba por tornar o controle sobre os recursos estaduais - e municipais - forte elemento estratégico para a continuidade da carreira política.

\section{CONSIDERAÇÕES FINAIS}

Nas décadas finais do século XX, o México vivenciou profundas transformações políticas. As reformas eleitorais iniciadas na década de 1970 propiciaram o aumento do papel das oposições partidárias, culminando no final do sistema de partido hegemônico e início da alternância. Nesse quadro, a questão da descentralização territorial ganha força. Se sob o sistema de partido hegemônico essa questão era colocada de lado e as demandas territoriais eram expressas apenas no interior do PRI, não tendo espaço institucional para a sua vazão, a partir do crescimento da representação dos partidos de oposição e a derrota do partido até então hegemônico em alguns estados, acaba por colocar o desenho do federalismo como questão importante na política mexicana. Como foi mostrado, esse processo tem, principalmente, dois eixos: o fiscal e o político. 
Sobre a questão do federalismo fiscal, nota-se uma descentralização tímida. Mesmo com alguns esforços na direção de maior distribuição de recursos fiscais, o México continua com uma alta arrecadação no nível federal, deixando pouco espaço de arrecadação para os outros níveis da federação. Isso torna os níveis subnacionais dependentes das distribuições de recursos financeiros feitos pela União. Porém, essa distribuição é realizada, em grande parte, obedecendo a critérios político-eleitorais e não formas claras e institucionalmente regulamentadas. Assim, essa centralização fiscal permite alta dose de controle do Executivo Nacional sobre os níveis subnacionais.

Por outro lado, a descentralização política apresenta um crescimento real nesse período, tornando as lideranças subnacionais importantes elementos na condução política do país, uma vez que elas controlam recursos essenciais para a carreira política. Desta forma, após o fim do período de partido hegemônico, a disputa eleitoral tira a figura do Presidente da República como líder partidário, os líderes estaduais passam a controlar o acesso às listas partidárias, a maior competição entre os partidos tiram a certeza de sucesso eleitoral dos membros do PRI, formam-se novas lideranças nos outros partidos. Somado a isso, o controle estadual sobre seu próprio calendário eleitoral aumenta a independência das lideranças subnacionais frente ao nacional, uma vez que elas podem casar ou isolar as eleições estaduais das disputas nacionais, conforme o que for mais vantajoso. Assim, as diferenças entre os níveis nacional e estadual mostram-se crescentes: as disputas eleitorais nos estados não repetem as apresentadas no âmbito nacional. Além disso, o crescimento de governos estaduais controlados por outros partidos que não o do Presidente da República força uma maior negociação entre os níveis de governo, algo que não ocorria no período anterior. Deste modo, a abertura política e a alternância permitiram que as demandas subnacionais encontrassem um caminho institucional para se expressar.

Todavia, a alta centralização fiscal ainda é um entrave para essa expressão. Mesmo contando com importantes recursos políticos, as lideranças subnacionais - em especial os governadores - ainda dependem das transferências feitas pela União. Essas transferências formam um forte elemento de coordenação territorial sob o controle do Executivo nacional, enfraquecendo a atuação autônoma dos governadores. 


\section{REFERÊNCIAS BIBLIOGRÁFICAS}

ALGAZI, L. B. 2012. ¿Quien Legisla en Mexico? Descentralizacion y proceso legislativo. Revista Mexicana de Sociologia, v. 74, n.4.

BADILLO, M. J. e RAMIREZ, G. L. 2009. Procesos Electorales em la república mexicana (19802009), Universidad Autónoma de Guerrero, Instituto Internacional de Estudios Políticos Avanzados.

CASAR, M. A. 2008. Los gobiernos sin mayoría em México: 1997-2006. Politica y Gobierno, v. XV, n.2.

COSTA, V, 2008. A dinâmica institucional da cooperação intergovernamental em Estados Federados: o caso brasileiro em perspectiva comparada, In: SERAINE, A. B. M. S., SANTOS JUNIOR, R. B., MIYAMOTO, S. Estado, desenvolvimento e políticas públicas. Ijuí: Ed. Ijuí; Teresina: Ed. UFPI.

FALLETI, T. G. 2010. Decentralization and subnational politics in Latin America. Cambridge: Cambridge University Press.

HERRERA, R.L.A.G. 2006. El federalismo fiscal realmente existente en las administraciones de los presidentes Ermesto Zedillo Ponce de Leon y Vicente Fox Quesada. Dissertação (mestrado). FLACSO- sede México.

MIZRAHI, Y. 2001 El federalismo y las políticas de descentralización en México. Foro Internacional de Federalismo, Veracruz.

MIZRAHI, Y. 2005. Mexico. In: GRIFFITHS, A. (org). Handbook of federal Countries. Forum of Federations; McGill-Queen's University Press.

NACIF, B. 2006. The fall of the dominant presidency: Lawmaking under divided government in Mexico, Documentos de trabajo del CIDE, n. 185.

NACIF, B. 2007. Para entender las instituiciones políticas del México democrático. Documentos de trabajo del CIDE, n.194.

VALDEZ, G. M. V. 2013 Circo de varias pistas. Análisis multinivel del sistema de partidos em Mexico. Trabalho apresentado no VII Congresso Latino Americano de Ciência Política, Bogotá. 